\title{
Impact of sodium-glucose cotransporter 2 inhibitors on blood pressure
}

\author{
This article was published in the following Dove Press journal: \\ Vascular Health and Risk Management \\ 27 October 2016 \\ Number of times this article has been viewed
}

\section{James W Reed}

Morehouse School of Medicine, Atlanta, GA, USA
Correspondence: James W Reed Grady Memorial Hospital for Morehouse School of Medicine, 720 Westview Drive SW, Atlanta, GA 30310-1495, USA

Tel +I 4047565788

Fax +I 404756 I3।3

Email jreed@msm.edu
Abstract: SGLT2 inhibitors are glucose-lowering agents used to treat type 2 diabetes mellitus (T2DM). These agents target the kidney to promote urinary glucose excretion, resulting in improved blood glucose control. SGLT2-inhibitor therapy is also associated with weight loss and blood pressure (BP) lowering. Hypertension is a common comorbidity in patients with T2DM, and is associated with excess morbidity and mortality. This review summarizes data on the effect of SGLT2 inhibitors marketed in the US (namely canagliflozin, dapagliflozin, or empagliflozin) on BP in patients with T2DM. Boolean searches were conducted that included terms related to BP or hypertension with terms for SGLT2 inhibitors, canagliflozin, dapagliflozin, or empagliflozin using PubMed, Google, and Google Scholar. Data from numerous randomized controlled trials of SGLT2 inhibitors in patients with T2DM demonstrated clinically relevant reductions in both systolic and diastolic BP, assessed via seated office measurements and 24-hour ambulatory BP monitoring. Observed BP lowering was not associated with compensatory increases in heart rate. Circadian BP rhythm was also maintained. The mechanism of SGLT2 inhibitor-associated BP reduction is not fully understood, but is assumed to be related to osmotic diuresis and natriuresis. Other factors that may also contribute to BP reduction include SGLT2 inhibitor-associated decreases in body weight and reduced arterial stiffness. Local inhibition of the renin-angiotensin-aldosterone system secondary to increased delivery of sodium to the juxtaglomerular apparatus during SGLT2 inhibition has also been postulated. Although SGLT2 inhibitors are not indicated as BP-lowering agents, the modest decreases in systolic and diastolic BP observed with SGLT2 inhibitors may provide an extra clinical advantage for the majority of patients with T2DM, in addition to improving blood glucose control.

Keywords: blood pressure, canagliflozin, dapagliflozin, empagliflozin, sodium-glucose cotransporter 2 inhibitors, type 2 diabetes

\section{Type 2 diabetes mellitus and hypertension}

Hypertension is a common comorbidity in patients with type 2 diabetes mellitus (T2DM), with the prevalence of T2DM in US patients ranging from $67 \%$ to $87 \%$ (where hypertension was defined as blood pressure $[\mathrm{BP}] \geq 140 / 90, \geq 130 / 85$, or $\geq 130 / 80 \mathrm{mmHg}$, and/or the use of antihypertensive medication).$^{1-3}$ Hypertension is a major risk factor for cardiovascular (CV) disease ${ }^{4}$ (such as angina, myocardial infarction, and heart failure) and diabetes microvascular complications. ${ }^{5}$ The pathophysiology of hypertension in patients with diabetes is complex and not currently well understood. ${ }^{6} \mathrm{~A}$ variety of mechanisms are believed to contribute: ${ }^{7}$ principally, sympathetic nervous system overactivity, renin-angiotensin-aldosterone system (RAAS) activation, and abnormal renal sodium handling, as well as endothelial dysfunction, damage to small and large 
arteries, impaired insulin-mediated vasodilatation, dysfunctional immune responses, and inflammation.

$\mathrm{BP}$ reduction is associated with decreased risk of T2DMrelated micro- and macrovascular complications. ${ }^{8,9}$ Although exact targets for reduction have not been definitively shown, data from UK Prospective Diabetes Study (UKPDS) 36 (observational analysis cohort, $\mathrm{N}=3,642$, mean systolic BP [after 3-month dietary run-in] $135 \mathrm{mmHg}$; results compared to those from UKPDS 38 study cohort, $\mathrm{N}=1,148$, baseline mean systolic BP $159 \mathrm{mmHg}$ ) suggested that each $10 \mathrm{mmHg}$ reduction in systolic BP was associated with a $12 \%$ decrease in the risk of any end point related to diabetes (95\% confidence interval $[\mathrm{CI}] 10 \%-14 \%, P<0.0001)$ and a $15 \%$ reduction in the risk of diabetes-related death $(95 \% \mathrm{CI}$ $12 \%-18 \%, P<0.0001) .{ }^{9}$ The benefit of $\mathrm{BP}$ reduction was confirmed by a recent meta-analysis involving more than 100,000 participants with T2DM who showed a significantly lower risk of mortality, CV events, coronary heart disease, stroke, albuminuria, and retinopathy for each $10 \mathrm{mmHg}$ systolic BP reduction. ${ }^{10}$ When the trials were stratified by mean baseline systolic BP ( $\geq 140$ or $<140 \mathrm{mmHg}$ ), studies with baseline systolic BP $\geq 140 \mathrm{mmHg}$ had lower risks of outcomes other than stroke, retinopathy, and renal failure. ${ }^{10}$

Recommendations for target BP in patients with diabetes have been debated; ${ }^{11}$ however, recent guidelines from various clinical societies have largely recommended a systolic BP target of $<140 \mathrm{mmHg}$ for people with diabetes, with the option to individualize treatment to lower systolic targets (ie, $<130 \mathrm{mmHg}$ ) if this can be achieved without undue treatment burden. ${ }^{5,11-14}$ Although the lack of evidence from randomized clinical trials to support lower BP targets in diabetes has been recorded, ${ }^{15}$ some societies advocate more aggressive BP lowering (ie, $<130 / 80 \mathrm{mmHg}$ ), ${ }^{16-18}$ as supported by several recent publications. ${ }^{10,19,20}$ Regardless of which goal is used, however, a significant proportion of patients with diabetes fail to achieve their target BP. ${ }^{21}$

The aim of this review is to summarize data on the effect of sodium-glucose cotransporter 2 (SGLT2) inhibitors marketed in the US (namely canagliflozin, dapagliflozin, or empagliflozin) on BP in patients with T2DM. SGLT2 inhibitors that are not marketed in the US and/or those currently in clinical development are not discussed herein.

\section{Methods of evidence acquisition}

Boolean searches were conducted that included terms related to BP or hypertension with terms for SGLT2 inhibitors, canagliflozin, dapagliflozin, or empagliflozin using PubMed, Google, and Google Scholar.

\section{SGLT2 inhibitors in the treatment of patients with T2DM Mechanism of action and rationale}

The mechanism of action of SGLT2 inhibitors has been described in detail previously. ${ }^{22-24}$ Briefly, fluid and solutes (eg, glucose) from the plasma are filtered via the kidney glomerulus. The glomerular filtrate then enters the kidney tubule, where much of it is reabsorbed and returned to the blood circulation, while the remainder undergoes urinary excretion. In otherwise-healthy individuals, essentially all of the glucose in the filtrate is reabsorbed, and virtually none is lost in the urine. ${ }^{22}$ SGLT2, a sodium-glucose cotransporter protein located in the early proximal kidney tubule, is the major pathway for renal glucose reabsorption. ${ }^{25,26}$ An additional sodium-glucose cotransporter protein, SGLT1, has a lesser role in glucose reabsorption in the kidney. ${ }^{22,25}$ The expression and activity of SGLT2 is enhanced in individuals with T2DM, resulting in increased glucose reabsorption and maintenance of hyperglycemia. ${ }^{23,27}$ Pharmacologic inhibition of SGLT2 in the kidney reduces glucose reabsorption and promotes urinary glucose excretion, thereby leading to the correction of hyperglycemia. ${ }^{23}$ Inhibition of SGLT2 reduces the capacity for renal glucose reabsorption by $30 \%-50 \%{ }^{28}$ Currently, three SGLT2 inhibitors are approved in the US for clinical use in the treatment of T2DM: canagliflozin, dapagliflozin, and empagliflozin. ${ }^{29-31}$ These agents also have marketing approval in the EU, and in other parts of the world.

\section{Summary of efficacy and safety}

Data from numerous clinical trials in patients with T2DM have demonstrated that SGLT2 inhibitors reduce the concentration of both glycated hemoglobin $\left(\mathrm{HbA}_{\mathrm{lc}}\right)$ and fasting plasma glucose (FPG), ${ }^{32-34}$ thereby improving glucose control. ${ }^{35}$ This leads to improved pancreatic $\beta$-cell function and decreased insulin resistance. ${ }^{36-38}$ SGLT2-inhibitor therapy is also associated with reductions in body weight of $1.6-2.8 \mathrm{~kg}$ versus placebo, per data from meta-analyses of SGLT2inhibitor clinical trials (duration $12-78$ weeks). ${ }^{32-34}$ Reductions in body-fat mass accounted for $68 \%-90 \%$ of the weight loss associated with SGLT2-inhibitor therapy, as reported in further clinical trials (duration 52-104 weeks). ${ }^{39-41} \mathrm{~A}$ further study observed that SGLT2 inhibitor-induced urinary glucose excretion resulted in the loss of approximately $200 \mathrm{kcal} /$ day (empagliflozin $25 \mathrm{mg}$ once daily for 90 weeks; $\mathrm{N}=86$ ). ${ }^{42}$ During this study, patients achieved only around $30 \%$ of the weight loss predicted by their urinary glucose excretion (ie, $-3.2 \pm 4.2 \mathrm{~kg}$ actual vs $-11.3 \pm 3.1 \mathrm{~kg}$ predicted), which was 
attributed to dietary compensation of urinary calorie loss. ${ }^{42}$ Modest reductions in systolic BP $(3-6 \mathrm{mmHg})$ were reported during SGLT2-inhibitor clinical trials. ${ }^{43}$

SGLT2 inhibitors are generally well tolerated, albeit with some commonly associated adverse events (AEs), such as an increased risk of genital mycotic infections in some patients. ${ }^{29-31}$ Clinical trial data show that SGLT2 inhibitors are associated with a low risk of hypoglycemia, unless coadministered with insulin or an insulin secretagogue. ${ }^{32-34}$ Osmotic diuresis with subsequent intravascular volume contraction induced by SGLT2 inhibitors could potentially pose a risk of volume-depletion AEs (eg, hypotension) in patients prone to these conditions (eg, those with renal impairment, low systolic BP, coadministration of diuretic therapy, and elderly patients). ${ }^{29-31}$ There have also been postmarketing reports of diabetic ketoacidosis (DKA), ${ }^{44,45}$ and product labels were revised to include this safety issue. ${ }^{29-31}$ Blood glucose levels were only slightly or moderately increased (ie, euglycemic ketoacidosis) in a number of occurrences of DKA. ${ }^{44,46-48}$ Potential contributory factors for DKA were identified in many cases (eg, major illness or surgery, reduced intake of food and fluid, reduced insulin dose, alcohol intake, and recent exercise). ${ }^{44,46,49}$ The frequency of reported DKA events in populations from randomized controlled trials (RCTs) of US-marketed SGLT2 inhibitors was $<0.1 \%{ }^{49,50}$ There have also been postmarketing reports of urosepsis and pyelonephritis, ${ }^{45}$ a warning on which was added to the respective product labels..$^{29-31}$

\section{SGLT2 inhibitors and BP control Potential mechanisms of action of SGLT2 inhibitors relating to $\mathrm{BP}$ control}

BP reduction by SGLT2 inhibitors is thought possibly to be related to their effects on osmotic diuresis and mild natriuresis. $^{51,52}$ Osmotic diuresis leads to the excretion of glucose and water caused by the presence of unreabsorbed glucose in the kidney-tubule fluid, due to SGLT2 inhibition. Increased urinary output ranging from approximately $110 \mathrm{~mL} /$ day to $470 \mathrm{~mL} /$ day has been documented in patients treated with SGLT2 inhibitors. ${ }^{53}$ Enhanced sodium excretion may contribute to reduced plasma volume and lower BP, but data on urinary sodium excretion from clinical trials are limited. ${ }^{51}$ In addition, ongoing urinary sodium loss has not been reported with SGLT2 inhibitors, and there is quick compensation for the mild natriuresis that may occur. ${ }^{54}$ A reduction in plasma volume is also consistent with the significant increase in hematocrit observed with SGLT2 inhibitors versus placebo or active comparators in a meta-analysis of 14 RCTs. ${ }^{51}$ In a 12-week study of T2DM patients $(\mathrm{N}=75)$ receiving dapagliflozin (10 mg/day) versus placebo or hydrochlorothiazide (HTZ; $25 \mathrm{mg} /$ day), hematocrit increased by 2.2 (95\% CI 1.3-3) in the dapagliflozin group versus changes of -0.2 (95\% CI -1 to 0.6$)$ and $-0.9(95 \% \mathrm{CI}-2.3$ to 0.6$)$ for the placebo and HTZ groups, respectively. ${ }^{55}$ A substudy $(\mathrm{N}=30)$ observed loss of plasma volume (median $-7.3 \%$; interquartile range [IQR] -12.4 to -4.8$)$ in the dapagliflozin group versus placebo and HTZ groups (median 5.2\%, IQR -2.5 to 8.7 , and median $2.8 \%$, IQR -10.6 to 25.7 , respectively). ${ }^{55}$

SGLT2 inhibitor-associated decreases in body weight may also contribute to BP reduction. This is considered unlikely by some researchers, however, as the BP-lowering effect occurs earlier than any significant weight loss. ${ }^{52} \mathrm{BP}$ reductions are associated with weight loss, as evidenced in clinical trials and epidemiologic studies ${ }^{56-58}$ in which reductions in systolic BP associated with weight loss in patients with T2DM have been reported. ${ }^{59}$ The weight loss observed during the first weeks after treatment initiation with an SGLT2 inhibitor is presumed to be mainly due to volume contraction, rather than to the loss of fat and/or lean tissue. ${ }^{54}$ As discussed earlier, a reduction in fat-tissue mass has been observed in long-term studies with SGLT2 inhibitors, ${ }^{39-41}$ but its impact on BP lowering has not been evaluated. ${ }^{54}$ Furthermore, an analysis of data pooled from four placebo-controlled Phase III studies using canagliflozin in patients with T2DM $(\mathrm{N}=2,250$; primary assessment at 26 weeks) estimated that weight loss-associated mechanisms contributed approximately $40 \%$ to the overall reduction in systolic BP. ${ }^{60}$ Cefalu et al stated that the exact mechanism of weight loss-independent BP reduction with SGLT2 inhibitors was not fully understood, ${ }^{60}$ and speculated that if osmotic diuresis were the major mechanism, then smaller BP-lowering effects in patients with renal impairment might be anticipated. ${ }^{60}$

An additional explanation for BP reduction by SGLT2 inhibitors is the local inhibition of the RAAS secondary to increased delivery of sodium to the juxtaglomerular apparatus. ${ }^{61-63}$ Data from animal models of diabetes supporting the tubular hypothesis for diabetic nephropathy demonstrated that the SGLT2 inhibitor-associated reduction in proximal tubular reabsorption of sodium caused tubuloglomerular feedback, via increased sodium delivery to the macula densa, and resulted in production of the potent vasoconstrictor adenosine, afferent arteriolar vasoconstriction, and decreased renal blood flow. ${ }^{64}$ This may be related to a postulated renoprotective role for SGLT2 inhibitors, ${ }^{64}$ and dedicated renal outcome trials are ongoing (NCT01989754 and NCT02065791).

Further proposed mechanisms for BP control include possible indirect effects on nitric oxide release secondary to reduced oxidant stress caused by improved glycemic control (observations from preliminary studies only). ${ }^{52}$ The effect of SGLT2 
inhibitors on reduction of arterial stiffness and its relationship to BP lowering has been investigated for empagliflozin. In an analysis of patients with T2DM (cohort 1, hypertensive population from one 12-week Phase III study, $\mathrm{N}=823$; cohort 2 , pooled population from four 24-week Phase III studies, $\mathrm{N}=2,477$ ), empagliflozin significantly reduced markers of arterial stiffness in both cohorts. ${ }^{65}$ A study of normotensive patients with T1DM who received empagliflozin $(25 \mathrm{mg} /$ day for 8 weeks; $\mathrm{N}=40$ ) reported that empagliflozin was associated with a reduction in arterial stiffness. ${ }^{66}$ These changes were not explained by activity in the RAAS, endothelial nitrous oxide, or the sympathetic nervous system, and the authors postulated that other factors may be involved. ${ }^{66}$ These may include weight loss, decreased insulin dose, direct effects on vascular smooth muscle, and anti-inflammatory effects associated with SGLT2inhibitor treatment. ${ }^{66}$

\section{Clinical studies and BP data}

A summary of the mean changes in systolic and diastolic BP reported during key Phase III RCTs investigating the efficacy and safety of canagliflozin, dapagliflozin, and empagliflozin in patients with T2DM is presented in Table $1,{ }^{67-81}$ and includes analyses of pooled data. ${ }^{65,82,83}$ During these studies, seated systolic and diastolic BP (ie, office BP) were commonly measured. The placebo-subtracted mean difference from baseline to the end of treatment (24-26 weeks) ranged from -1.4 to $-6.6 \mathrm{mmHg}$ for systolic BP and -0.4 to $-2.5 \mathrm{mmHg}$ for diastolic BP. It should be noted that these relatively modest changes in BP reflect the fact that these studies were performed in patients with well-controlled BP at baseline.

Analysis of pooled data from canagliflozin RCTs in patients with T2DM (four Phase III studies; $\mathrm{N}=2,313$ ) reported the following placebo-subtracted mean differences from baseline to the end of treatment in BP for canagliflozin $100 \mathrm{mg} /$ day and $300 \mathrm{mg} /$ day groups, respectively: systolic BP, $-4 \mathrm{mmHg}$ (95\% CI -5.1 to -2.8$)$ and $-4.7 \mathrm{mmHg}(95 \% \mathrm{CI}-5.8$ to -3.5$)$; diastolic BP, $-1.9 \mathrm{mmHg}(95 \% \mathrm{CI}-2.6$ to -1.2$)$ and $-1.9 \mathrm{mmHg}(95 \% \mathrm{CI}-2.6$ to -1.1$) .{ }^{82}$ Canagliflozin $100 \mathrm{mg}$ and $300 \mathrm{mg}$ were associated with an increased frequency of osmotic diuresis-related AEs (eg, increased urine volume, increased urine frequency) versus placebo (6.7\% and $5.6 \%$ vs $0.8 \%$, respectively), but the frequency of intravascular volume reduction-related AEs (eg, orthostatic hypotension and postural dizziness) was similar for all groups $(1.2 \%$ and $1.3 \%$ vs $1.1 \%$, respectively). ${ }^{82}$ Minimal mean changes in heart rate were observed $(-0.6 \mathrm{bpm},-0.4 \mathrm{bpm}$, and $0 \mathrm{bpm}$ for canagliflozin $100 \mathrm{mg}, 300 \mathrm{mg}$, and placebo, respectively). ${ }^{82}$ Small increases in hematocrit were observed with canagliflozin $100 \mathrm{mg}$ and $300 \mathrm{mg}$ versus placebo $(5.8 \%$ and
$6.35 \%$ vs $0.2 \%$, respectively). ${ }^{82}$ A larger analysis of data pooled from dapagliflozin RCTs (13 Phase IIB/III studies; $\mathrm{N}=4,655)$ stratified the patient population into those with and without hypertension at baseline (nonhypertensive was defined as systolic BP $\leq 140 \mathrm{mmHg}$ and hypertensive as systolic BP >140 mmHg). ${ }^{83}$ Placebo-subtracted mean differences from baseline to the end of treatment in BP for the dapagliflozin group (10 mg/day) were as follows: systolic $\mathrm{BP}$ in hypertensive patients, $-3.6 \mathrm{mmHg}$ (95\% CI -4.9 to -2.4 ); systolic BP in nonhypertensive patients, $-2.6 \mathrm{mmHg}$ (95\% CI -3.4 to -1.8$)$; diastolic BP in hypertensive patients, $-1.2 \mathrm{mmHg}(95 \% \mathrm{CI}-2$ to -0.4$)$; diastolic BP in nonhypertensive patients, $-1.2 \mathrm{mmHg}(95 \% \mathrm{CI}-1.8$ to -0.7$) .{ }^{83}$ No clinically relevant mean change in heart rate was observed for either treatment group. ${ }^{83} \mathrm{~A}$ similar proportion of hypertensive patients in both treatment groups had an episode of measured orthostatic hypotension (defined as a decrease of $>20 \mathrm{mmHg}$ in systolic BP or $>10 \mathrm{mmHg}$ in diastolic BP from a supine to a standing position): $17.4 \%$ and $15.5 \%$ for dapagliflozin and placebo, respectively. ${ }^{83}$ Orthostatic hypotension reported as AEs were uncommon (data not stated), and none were classified as serious. ${ }^{83}$ For empagliflozin, a pooled analysis of four Phase III studies ( $\mathrm{N}=2,477,10 \mathrm{mg}$ /day and $25 \mathrm{mg} /$ day groups were pooled, seated office BP measured) reported placebo-subtracted mean differences from baseline to the end of treatment in BP of $-3.6 \mathrm{mmHg}(95 \% \mathrm{CI}-4.5$ to -2.7 , $P<0.001)$ for systolic BP and $-1.3 \mathrm{mmHg}(95 \% \mathrm{CI}-1.9$ to $-0.8, P<0.001)$ for diastolic BP. ${ }^{65}$ Minimal mean change in 24-hour heart rate was observed for empagliflozin $(-0.9 \mathrm{bpm}$ vs $-0.1 \mathrm{bpm}$ for placebo). ${ }^{65}$ Events consistent with volume depletion were reported in $0.2 \%$ (two patients) receiving placebo versus $0.3 \%$ (five patients) receiving empagliflozin. ${ }^{65}$

To date, three dedicated Phase III RCTs to investigate the efficacy and safety of SGLT2 inhibitors in patients with T2DM and hypertension have been published: the dapagliflozin BP study, ${ }^{84}$ the EMPA-REG BP study, ${ }^{85}$ and the canagliflozin BP study. ${ }^{86}$ The main results from these trials are summarized in Table 2. ${ }^{84-86}$ Unlike the other SGLT2-inhibitor Phase III RCTs, these dedicated BP studies required the dose and regimen of background BP-lowering agents to be stable during the study treatment period, and reported the change from baseline in BP as a coprimary end point. BP investigations for these studies included seated measurements and ambulatory BP monitoring (ABPM). EMPA-REG BP and canagliflozin BP studies used ABPM in the primary BP efficacy outcome, ${ }^{85,86}$ whereas it was used as a secondary BP end point in the dapagliflozin $\mathrm{BP}$ trial. ${ }^{84} \mathrm{ABPM}$ is becoming increasingly recommended for use in the diagnosis and assessment of hypertension. ${ }^{87} \mathrm{ABPM}$ has been shown to be a more sensitive predictor of clinical CV 
Table I Summary of efficacy of canagliflozin, dapagliflozin, and empagliflozin in reducing systolic and diastolic BP in patients with T2DM

\begin{tabular}{|c|c|c|c|c|c|c|c|c|c|c|c|c|c|}
\hline \multirow{4}{*}{$\begin{array}{l}\text { Clinical trial } \\
\text { categories }\end{array}$} & \multicolumn{12}{|c|}{ Placebo-subtracted mean BP change from baseline, $\mathrm{mmHg}^{\mathrm{a}}$} & \multirow[t]{4}{*}{ References } \\
\hline & \multicolumn{4}{|c|}{ Canagliflozin } & \multicolumn{4}{|c|}{ Dapagliflozin } & \multicolumn{4}{|c|}{ Empagliflozin } & \\
\hline & \multicolumn{2}{|c|}{ Systolic BP } & \multicolumn{2}{|c|}{ Diastolic BP } & \multicolumn{2}{|c|}{ Systolic BP } & \multicolumn{2}{|c|}{ Diastolic BP } & \multicolumn{2}{|c|}{ Systolic BP } & \multicolumn{2}{|c|}{ Diastolic BP } & \\
\hline & $100 \mathrm{mg}$ & $300 \mathrm{mg}$ & $100 \mathrm{mg}$ & $300 \mathrm{mg}$ & $5 \mathrm{mg}$ & $10 \mathrm{mg}$ & $5 \mathbf{~ m g}$ & $10 \mathrm{mg}$ & $10 \mathrm{mg}$ & $25 \mathrm{mg}$ & $10 \mathrm{mg}$ & $25 \mathrm{mg}$ & \\
\hline \multicolumn{14}{|l|}{ Phase III trials ${ }^{b}$} \\
\hline Monotherapy & -3.7 & -5.4 & -1.6 & -2.0 & -1.4 & -2.7 & -1.0 & -1.3 & -2.6 & -3.4 & -0.6 & -1.5 & $67-69$ \\
\hline Add-on to MET & -5.4 & -6.6 & -2.5 & -2.4 & -4.1 & -4.9 & -2.4 & -1.7 & -4.1 & -4.8 & -1.9 & -1.6 & $70-72$ \\
\hline $\begin{array}{l}\text { Add-on to } \\
\text { MET + SU }\end{array}$ & -2.2 & -1.6 & -1.1 & -0.5 & $\begin{array}{l}\text { Not } \\
\text { used }\end{array}$ & $-3.8^{c}$ & $\begin{array}{l}\text { Not } \\
\text { used }\end{array}$ & $\begin{array}{l}\text { Not } \\
\text { stated }\end{array}$ & -2.7 & -2.1 & -0.4 & -0.4 & $73-75$ \\
\hline $\begin{array}{l}\text { Add-on to } \\
P I O \pm \text { MET }\end{array}$ & -4.1 & -3.5 & -2.4 & -2.6 & -2.1 & -4.7 & -1.7 & -3.8 & -3.9 & -4.7 & -1.8 & -2.5 & $76-78$ \\
\hline Add-on to INS & $-2.3^{\mathrm{d}}$ & $-4.1^{d}$ & $-1.0^{\mathrm{d}}$ & $-1.7^{d}$ & $-2.4^{e}$ & $-3.1^{\mathrm{e}}$ & $-1.2^{\mathrm{e}}$ & $-0.8^{\mathrm{e}}$ & $-3.4^{4}$ & $-3.0^{f}$ & $-3.3^{f}$ & $-1.7^{f}$ & $79-81$ \\
\hline $\begin{array}{l}\text { Pooled data } \\
\text { from RCTs }\end{array}$ & & & & & & & & & & & & & $65,82,83$ \\
\hline $\begin{array}{l}\text { Overall } \\
\text { population }\end{array}$ & -4.0 & -4.7 & -1.9 & -1.9 & $\begin{array}{l}\text { Not } \\
\text { stated }\end{array}$ & $\begin{array}{l}\text { Not } \\
\text { stated }\end{array}$ & $\begin{array}{l}\text { Not } \\
\text { stated }\end{array}$ & $\begin{array}{l}\text { Not } \\
\text { stated }\end{array}$ & $\begin{array}{l}-3.6(\mathrm{pc} \\
\text { both do }\end{array}$ & $\begin{array}{l}\text { oled for } \\
\text { ses) }\end{array}$ & $\begin{array}{l}-1.3 \text { (po } \\
\text { both dos }\end{array}$ & $\begin{array}{l}\text { oled for } \\
\text { ses) }\end{array}$ & \\
\hline $\begin{array}{l}\text { Not hypertensive } \\
\text { at baseline }\end{array}$ & $\begin{array}{l}\text { Not } \\
\text { reported }\end{array}$ & $\begin{array}{l}\text { Not } \\
\text { reported }\end{array}$ & $\begin{array}{l}\text { Not } \\
\text { reported }\end{array}$ & $\begin{array}{l}\text { Not } \\
\text { reported }\end{array}$ & $\begin{array}{l}\text { Not } \\
\text { used }\end{array}$ & $-2.6^{8}$ & $\begin{array}{l}\text { Not } \\
\text { used }\end{array}$ & $-1.2^{\mathrm{g}}$ & Not rep & orted & Not repc & orted & \\
\hline $\begin{array}{l}\text { Hypertensive at } \\
\text { baseline }\end{array}$ & $-6.0^{\mathrm{h}}$ & $-7.4^{\mathrm{h}}$ & $+1.5^{\mathrm{h}}$ & $-1.6^{\mathrm{h}}$ & $\begin{array}{l}\text { Not } \\
\text { used }\end{array}$ & $-3.6^{8}$ & $\begin{array}{l}\text { Not } \\
\text { used }\end{array}$ & $-1.2^{8}$ & Not rep & orted & Not repc & orted & \\
\hline
\end{tabular}

Notes: aData presented for patients in the main/primary randomized controlled cohort from each trial listed (ie, not for high glycemic or exploratory cohorts). ${ }^{\mathrm{b}}$ Time to BP end point 24 or 26 weeks, unless otherwise stated. ${ }^{\circ}$ Time to systolic BP end point 8 weeks. ${ }^{d}$ Time to BP end point 18 weeks; INS regimens used: basal only ( $10 \%$

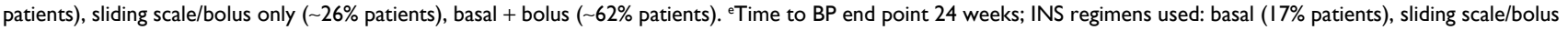
(83\% patients). 'Time to BP end point 18 weeks; all patients used basal INS regimen. ${ }^{8}$ Study defined nonhypertensive as baseline systolic BP $\leq 140$ mmHg and hypertensive as baseline systolic BP $>140 \mathrm{mmHg}$; diastolic BP was also measured in each group. ${ }^{83} \mathrm{hPatients}$ with elevated $\mathrm{BP}$ at baseline: systolic BP $\geq 140 \mathrm{mmHg}$ or diastolic BP $\geq 90 \mathrm{mmHg} .{ }^{82}$ Abbreviations: BP, blood pressure; INS, insulin; MET, metformin; PIO, pioglitazone; RCT, randomized controlled trial; SU, sulfonylurea; T2DM, type 2 diabetes mellitus.

outcomes than conventional office BP measurement, and also avoids the so-called white-coat effect that may be associated with office BP measurement. ${ }^{88}$

The dapagliflozin BP study ( $\mathrm{N}=449$ ) reported a significant reduction in mean seated systolic BP from baseline to week 12 in the dapagliflozin $10 \mathrm{mg}$ group compared with the placebo group (placebo-subtracted mean difference for dapagliflozin $-4.28 \mathrm{mmHg}, 95 \% \mathrm{CI}-6.54$ to $-2.02 ; P=0.0002) .{ }^{84}$ A similar trend was observed for mean seated diastolic BP, but was not statistically significant. ${ }^{84}$ Mean reductions from baseline values were more pronounced in the dapagliflozin $10 \mathrm{mg}$ group than in the placebo group (placebo-subtracted mean difference for dapagliflozin $-4.45 \mathrm{mmHg}, 95 \% \mathrm{CI}$ -7.14 to $-1.76 ; P=0.0012$ ), as revealed by 24 -hour ABPM at week $12 .{ }^{84}$ With regard to safety assessments, AEs were similar between both treatment groups, and AEs related to renal function or volume depletion occurred in $\leq 1 \%$ of patients. ${ }^{84}$ Hyponatremia did not occur in either treatment group, and mean change in hematocrit at week 12 was $1.7 \%$ (95\% CI 1.3\%-2\%) for dapagliflozin $10 \mathrm{mg}$ and $0.3 \%$ (95\% CI $0 \%-0.7 \%)$ for placebo (assessed as a safety end point, thus $P$-value not reported) ${ }^{84}$ Seated heart rate at week 12 did not differ meaningfully from baseline values in either treatment group ( $-1.4 \mathrm{bpm}$ for dapagliflozin $10 \mathrm{mg}$ [baseline $77.1 \mathrm{bpm}$ ] vs $-0.5 \mathrm{bpm}$ for placebo [baseline $77 \mathrm{bpm}$ ]). ${ }^{84}$ Orthostatic hypotension (defined as a decrease $>20 \mathrm{mmHg}$ in systolic $\mathrm{BP}$ or $>10 \mathrm{mmHg}$ in diastolic $\mathrm{BP}$ from a supine to a standing position) was not reported by any patients as an $\mathrm{AE}$ at week 12, but was measured in seven (3\%) patients in the dapagliflozin $10 \mathrm{mg}$ group and four $(2 \%)$ patients in the placebo group. ${ }^{84}$

EMPA-REG BP $(\mathrm{N}=825)$ reported that mean 24-hour systolic BP via ABPM was significantly reduced from baseline to week 12 in both the empagliflozin $10 \mathrm{mg}$ and $25 \mathrm{mg}$ groups compared with the placebo group (placebo-subtracted mean difference $-3.44 \mathrm{mmHg}$ [95\% CI -4.78 to -2.09 ] for empagliflozin $10 \mathrm{mg}$ and $-4.16 \mathrm{mmHg}$ [95\% CI -5.5 to -2.83$]$ for empagliflozin $25 \mathrm{mg}, P<0.001$ for each). ${ }^{85} \mathrm{~A}$ similar trend was observed for mean 24-hour diastolic BP via ABPM, and the difference for each empagliflozin dose versus placebo was statistically significant $(P<0.001$ for each $) .{ }^{85}$ Changes in office systolic and diastolic BP were consistent with $\mathrm{ABPM}$, and were also statistically significant ${ }^{85}$ In a post hoc subgroup analysis of patients with uncontrolled versus controlled BP at baseline (defined as mean 24-hour systolic $\mathrm{BP} \geq 130 \mathrm{mmHg}$ or diastolic $\mathrm{BP} \geq 80 \mathrm{mmHg}$ vs $<130 / 80 \mathrm{mmHg}$, respectively), the uncontrolled BP subgroup had greater decreases in both mean 24-hour systolic and diastolic BP compared with placebo at week 12 than the controlled BP subgroup. ${ }^{85}$ In terms of safety, AEs consistent with volume depletion were reported by two patients (placebo, one patient; empagliflozin $10 \mathrm{mg}$, one patient) ${ }^{85}$ Sodium concentrations showed no meaningful change from 


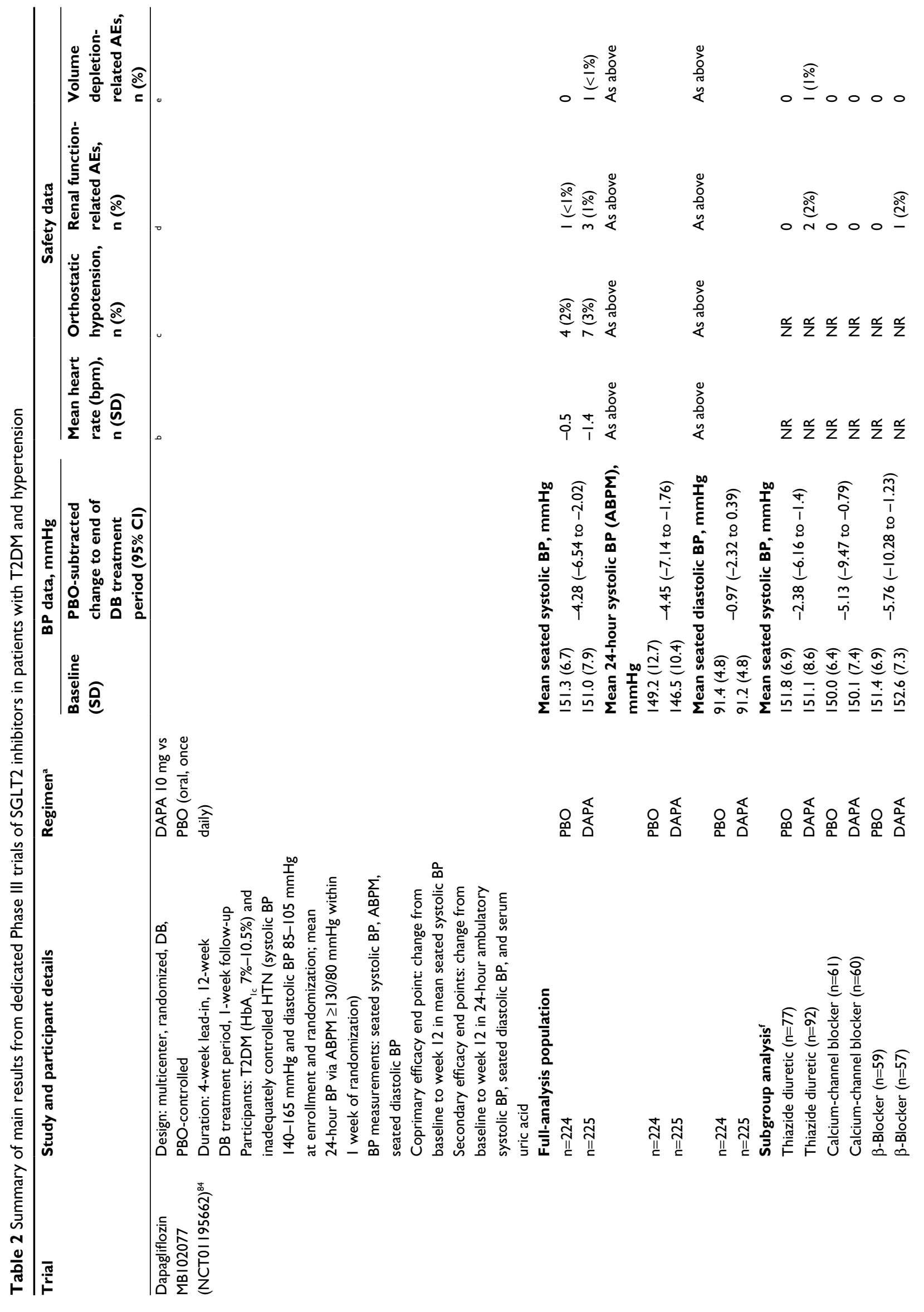




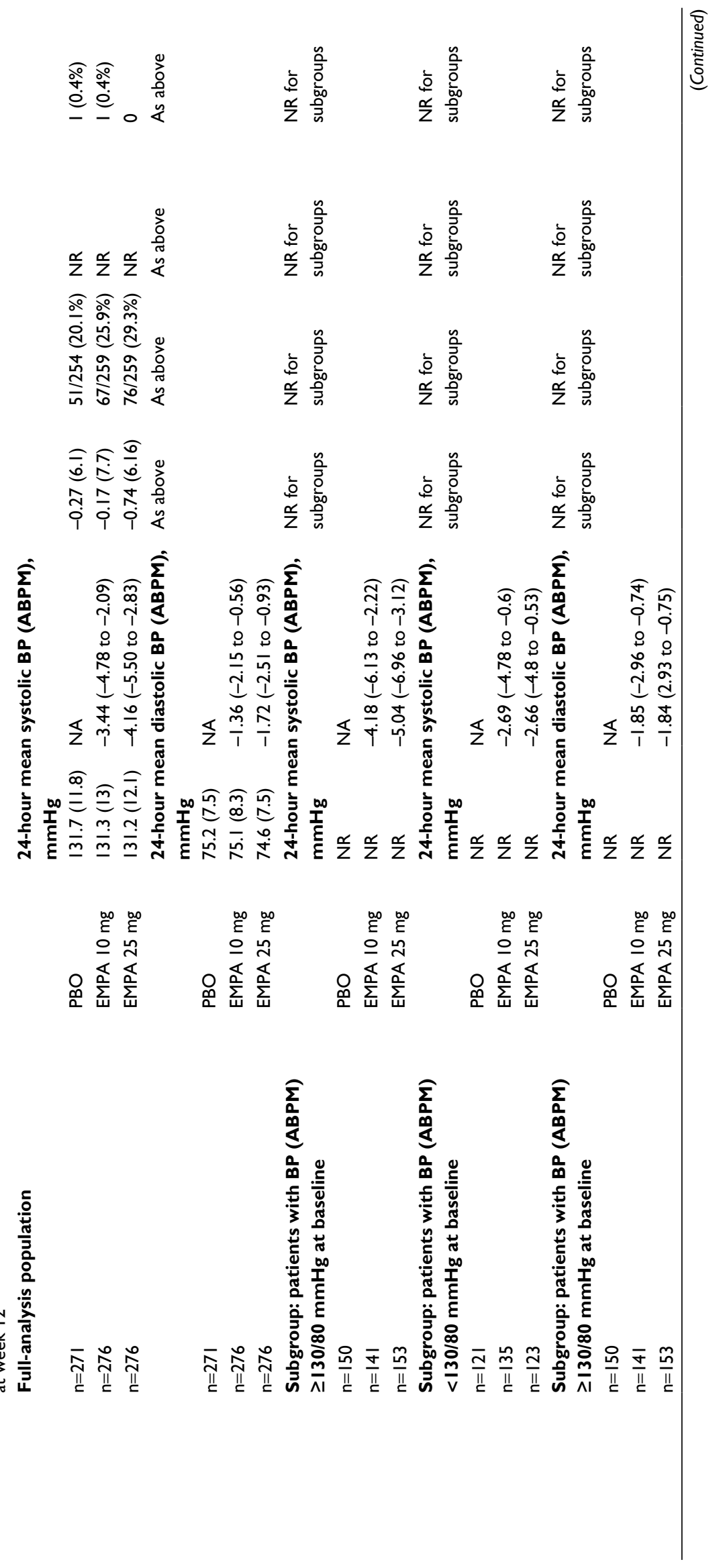

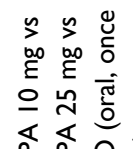

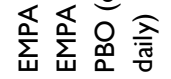

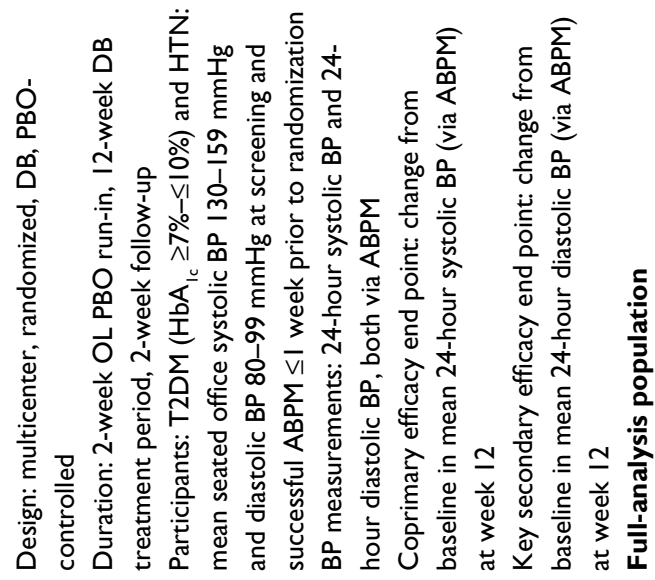

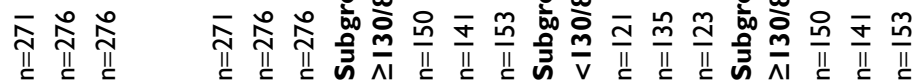

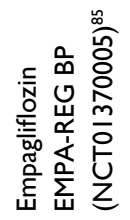




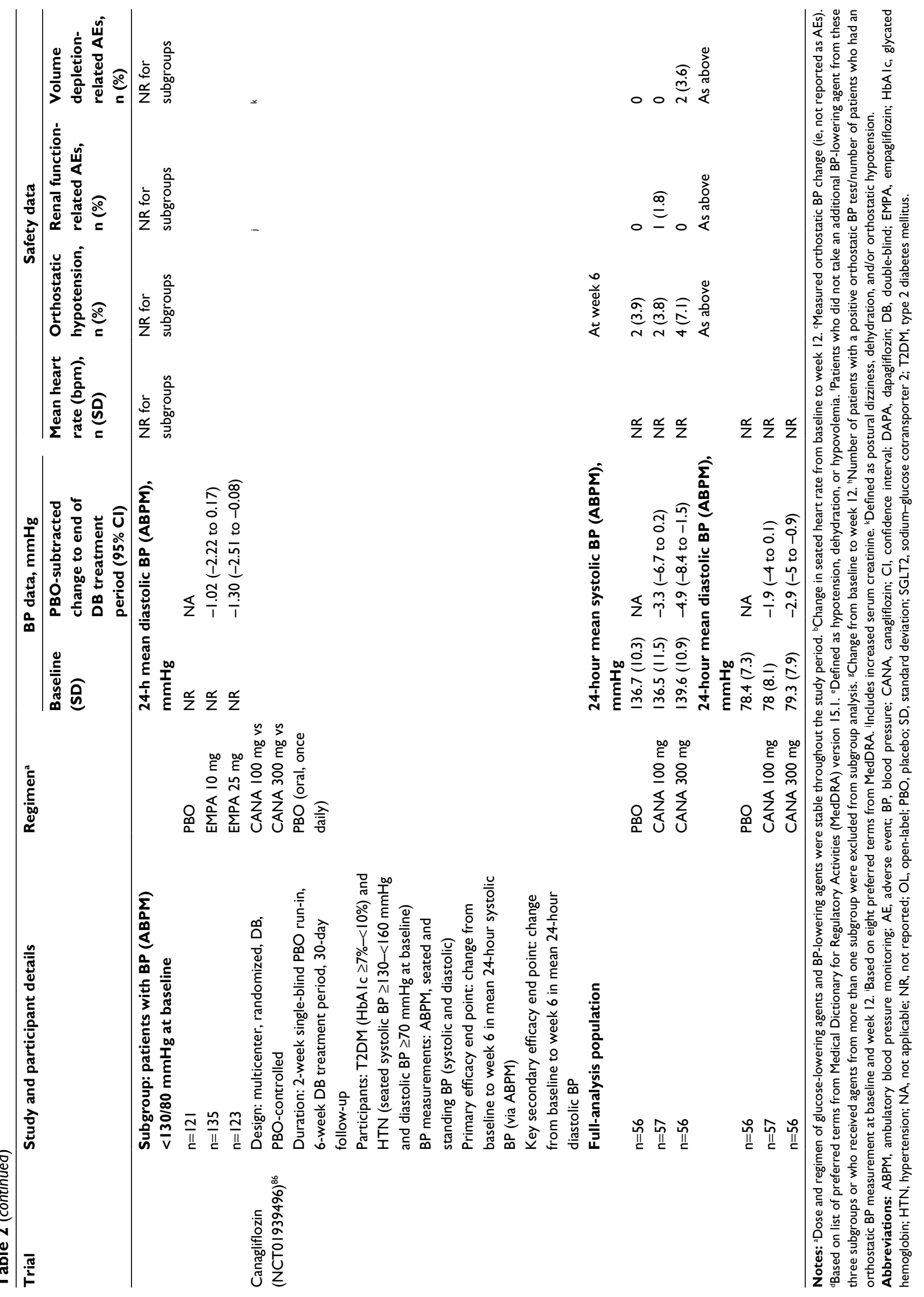


baseline in the placebo or empagliflozin-treatment groups (mean [SD, standard deviation] mmol/L: 0 [2] for placebo vs 0 [2] and 1 [2] for empagliflozin $10 \mathrm{mg}$ and $25 \mathrm{mg}$, respectively; $P$-values were not reported, as this was a safety end point). ${ }^{85}$ Mean change from baseline to end of treatment in hematocrit (SI unit expressed as a proportion of 1 [SD]) was 0 [0.02] for placebo versus 0.03 [0.02] and 0.02 [0.02] for empagliflozin $10 \mathrm{mg}$ and $25 \mathrm{mg}$, respectively. ${ }^{85}$ The proportion of patients with measured orthostatic hypotension (defined as positive if there was a decrease $\geq 20 \mathrm{mmHg}$ in systolic $\mathrm{BP}$ or $\geq 10 \mathrm{mmHg}$ in diastolic $\mathrm{BP}$ or an increase in pulse rate $\geq 20 \mathrm{bpm}$ between supine and standing readings) was greater in the empagliflozin groups than for placebo. Tikkanen et al reported that no patients in the empagliflozin groups with a positive orthostatic BP test had an AE that was potentially related to hypotension on the same day as the test..$^{85} \mathrm{BP}$ reductions were not associated with increased pulse rate from baseline to week 12 (mean changes in 24-hour heart rate via ABPM were $-0.27 \mathrm{bpm},-0.17 \mathrm{bpm}$, and $-0.74 \mathrm{bpm}$ for placebo, empagliflozin $10 \mathrm{mg}$, and empagliflozin $25 \mathrm{mg}$, respectively). ${ }^{85}$ In addition, a post hoc analysis suggested that empagliflozin may have beneficial effects on arterial stiffness and vascular resistance. ${ }^{65}$

The canagliflozin BP study ( $\mathrm{N}=169)$ reported that canagliflozin $300 \mathrm{mg}$ and $100 \mathrm{mg}$ provided greater reductions in mean 24-hour systolic BP (via ABPM) than placebo at week 6 (placebo-subtracted least squares [LS] mean changes: $-4.9 \mathrm{mmHg}$ [ $95 \% \mathrm{CI}-8.4$ to -1.5 ], $P=0.006$, and $-3.3 \mathrm{mmHg}$ [95\% CI -6.7 to 0.2 ], $P=0.062$, respectively). ${ }^{86}$ Mean 24-hour systolic BP showed numerical reductions for both canagliflozin dose groups compared with placebo at day 2 (placebo-subtracted LS mean changes: $-1.7 \mathrm{mmHg}$ [95\% CI -4.7 to 1.2$]$ and $-2 \mathrm{mmHg}$ [95\% CI -5 to 0.9 ] for canagliflozin $300 \mathrm{mg}$ and $100 \mathrm{mg}$, respectively) ${ }^{86}$ For diastolic BP, placebo-subtracted LS mean changes in 24-hour ABPM from baseline to week 6 were $-2.9 \mathrm{mmHg}(95 \% \mathrm{CI}-5$ to $-0.9, P=0.005$ ) for canagliflozin $300 \mathrm{mg}$ and $-1.9 \mathrm{mmHg}$ (95\% CI -4 to $0.1, P=0.062$ ) for canagliflozin $100 \mathrm{mg} .{ }^{86} \mathrm{The}$ incidence of AEs was higher in the canagliflozin $300 \mathrm{mg}$ and $100 \mathrm{mg}$ dose groups versus the placebo group (26.8\% and $26.3 \%$ vs $19.6 \%$, respectively). ${ }^{86}$ AEs related to volume depletion occurred in two patients (3.6\%); both were from the canagliflozin $300 \mathrm{mg}$ group. ${ }^{86} \mathrm{AEs}$ related to osmotic diuresis occurred in five patients (8.9\%) from the canagliflozin $300 \mathrm{mg}$ group, two (3.5\%) from the canagliflozin $100 \mathrm{mg}$ group, and three (5.4\%) from the placebo group. ${ }^{86}$ Significant orthostatic hypotension (defined as symptoms on standing [eg, dizziness, lightheadedness] or reduction in office BP [systolic $\mathrm{BP} \geq 20 \mathrm{mmHg}$ or diastolic $\mathrm{BP} \geq 15 \mathrm{mmHg}$ ] after
2 minutes of standing) at week 6 occurred in $7.1 \%(n=4)$, $3.8 \%(\mathrm{n}=2)$, and $3.9 \%(\mathrm{n}=2)$ for the canagliflozin $300 \mathrm{mg}$, $100 \mathrm{mg}$, and placebo groups, respectively. ${ }^{86}$

It should be noted that circadian BP rhythm was maintained in these dedicated hypertension studies of SGLT2 inhibitors, with greater reductions in daytime versus nighttime measurements observed for systolic $\mathrm{BP}^{84} 86$ and diastolic BP. ${ }^{85,86}$ Blunted nocturnal BP dipping, which is relatively common among patients with T2DM and hypertension, is associated with increased $\mathrm{CV}$ risk. ${ }^{89}$

A meta-analysis of 27 RCTs of SGLT2 inhibitors $(\mathrm{N}=12,960)$ assessed their BP-lowering ability, and included evaluations of canagliflozin (nine studies, $\mathrm{N}=5,607$ ), dapagliflozin (12 studies, $\mathrm{N}=5,280$ ), and empagliflozin (three studies, $\mathrm{N}=1,359) .{ }^{51}$ Compared with the control, SGLT2 inhibitors significantly reduced both systolic BP (weighted mean difference $-4 \mathrm{mmHg}, 95 \% \mathrm{CI}-4.4$ to -3.5 ) and diastolic BP (weighted mean difference $-1.6 \mathrm{mmHg}, 95 \% \mathrm{CI}-2.2$ to -1) from baseline.$^{51} \mathrm{~A}$ meta-analysis of $19 \mathrm{RCTs}$ evaluating canagliflozin (nine studies, $\mathrm{N}=5,285$ ) and dapagliflozin (eleven studies, $\mathrm{N}=4,788$ ) reported that these SGLT2 inhibitors had no significant effect on the incidence of orthostatic hypotension (relative risk $0.72,95 \%$ CI $0.47-1.09$ ). ${ }^{51}$

The trials discussed included predominantly white/ Caucasian participants, but a pooled analysis has allowed the study of black/African American individuals, a group disproportionately affected by T2DM, as well as diabetesrelated complications and hypertension. ${ }^{90} \mathrm{In}$ a recent pooled analysis of data from four Phase III RCTs for canagliflozin in patients with poorly controlled T2DM $(\mathrm{N}=4,158)$, black/ African Americans comprised 4\% $(\mathrm{N}=165)$ of the study population, and experienced significant reductions in systolic BP with canagliflozin (placebo-subtracted mean difference $-2.8 \mathrm{mmHg}$ [95\% CI -7.9 to -2.3 ] for canagliflozin $100 \mathrm{mg}$ and $-5.1 \mathrm{mmHg}$ [95\% CI -9.8 to -0.4 ] for canagliflozin $300 \mathrm{mg}){ }^{91}$ The first trial of an SGLT2 inhibitor conducted specifically in black/African American patients is underway, and is recruiting patients with hypertension plus uncontrolled T2DM; as such, it should provide particular insight into effects on BP as well as glucose control..$^{92}$ This trial (NCT02182830) will investigate empagliflozin ( $10 \mathrm{mg}$ or $25 \mathrm{mg}$, once daily) versus placebo, and is expected to complete in $2017 .^{92}$

\section{BP-lowering effects of SGLT2 inhibitors on CV outcomes in T2DM}

The ability of SGLT2 inhibitors to reduce BP and lower body weight, in addition to decreasing hyperglycemia, is indicative of their potential to reduce $\mathrm{CV}$ risk in patients 
with T2DM; however, the impact of their BP-lowering effect on CV outcomes is unknown. ${ }^{51}$ Nevertheless, several large RCTs to evaluate the CV safety of SGLT2 inhibitors are underway, ${ }^{93-97}$ and the empagliflozin CV outcomes trial (EMPA-REG OUTCOME) recently reported its results. ${ }^{98}$ $\mathrm{CV}$ outcomes trials for canagliflozin and dapagliflozin are estimated to complete in June 2017 and April 2019, respectively. ${ }^{93,95}$ During EMPA-REG OUTCOME, patients with T2DM and at high risk of CV events were randomized and treated with empagliflozin ( $10 \mathrm{mg}$ or $25 \mathrm{mg}$ once daily) or placebo, in addition to the standard of care. ${ }^{98}$ The primary outcome was a composite of $\mathrm{CV}$ death, nonfatal myocardial infarction (excluding silent myocardial infarction), or nonfatal stroke. ${ }^{98}$ EMPA-REG OUTCOME was the first dedicated $\mathrm{CV}$ outcomes study to demonstrate that a glucose-lowering agent (ie, of any drug class) lowered CV mortality and all-cause mortality, and reduced hospitalization for heart failure in patients with T2DM at high risk of $\mathrm{CV}$ events. ${ }^{98}$ From the study design, it is not possible to determine whether BP changes had any contribution to the $\mathrm{CV}$ outcomes, but despite the placebo group being more likely to receive additional BP-lowering drugs than empagliflozin-treated patients, the empagliflozin arms had small reductions in both systolic and diastolic BP for the duration of the trial. ${ }^{98}$ In a post hoc analysis of subgroups, there appeared to be a consistent benefit of empagliflozin treatment in patients with controlled and uncontrolled BP (defined as $<140 /<90 \mathrm{mmHg}$ and $\geq 140 / \geq 90 \mathrm{mmHg}$, respectively) for the primary outcome and for $\mathrm{CV}$ death, suggesting empagliflozin might benefit patients with and without hypertension..$^{98}$ It has been suggested that the observed impact on $\mathrm{CV}$ events and heart failure could be explained if empagliflozin caused a greater decrease in central aortic pressure than that evident from brachial artery BP measurement, and also reduced aortic stiffness. ${ }^{66,99}$ The reduction in hospitalization for heart failure reported during EMPA-REG OUTCOME is important for hypertensive patients with T2DM, given the association between elevated BP and heart failure. ${ }^{100}$ The results of the canagliflozin and dapagliflozin CV outcomes trials will determine if there is a class effect for SGLT2 inhibitors regarding $\mathrm{CV}$ outcomes, and may facilitate further analyses of any related BP effects.

\section{Conclusion}

Although SGLT2 inhibitors are not indicated as antihypertensive agents, the modest decreases in systolic and diastolic BP observed during SGLT2-inhibitor therapy may provide an extra clinical advantage for the majority of patients with T2DM, in addition to improving glucose control (via reductions in $\mathrm{HbA}_{1 \mathrm{c}}$ and FPG). Further studies are required to investigate the possible effects of SGLT2 inhibitors on vascular structure and function. Data from the remaining CV outcomes trials with SGLT2 inhibitors, in addition to those obtained from EMPA-REG OUTCOME, will provide clinicians with a clearer picture of the $\mathrm{CV}$ benefits of these agents in patients with T2DM, including those with hypertension.

\section{Acknowledgment}

The author received no direct compensation related to the development of the manuscript. Writing support was provided by Debra Brocksmith, $\mathrm{MB} \mathrm{ChB}, \mathrm{PhD}$ of Envision Scientific Solutions, which was contracted and funded by Boehringer Ingelheim Pharmaceuticals Inc (BIPI). BIPI was given the opportunity to review the manuscript for medical and scientific accuracy, as well as intellectual property considerations.

\section{Disclosure}

The author reports no conflicts of interest in this work.

\section{References}

1. Colosia AD, Palencia R, Khan S. Prevalence of hypertension and obesity in patients with type 2 diabetes mellitus in observational studies: a systematic literature review. Diabetes Metab Syndr Obes. 2013;6:327-338.

2. Centers for Disease Control and Prevention. National Diabetes Statistics Report, 2014. Atlanta: CDC; 2014.

3. Pantalone KM, Hobbs TM, Wells BJ, et al. Clinical characteristics, complications, comorbidities and treatment patterns among patients with type 2 diabetes mellitus in a large integrated health system. $B M J$ Open Diabetes Res Care. 2015;3(1):e000093.

4. Rapsomaniki E, Timmis A, George J, et al. Blood pressure and incidence of twelve cardiovascular diseases: lifetime risks, healthy life-years lost, and age-specific associations in 1.25 million people. Lancet. 2014;383(9932):1899-1911.

5. American Diabetes Association. Cardiovascular disease and risk management. Diabetes Care. 2016;39(Suppl 1):S60-S71.

6. Lorber D. Importance of cardiovascular disease risk management in patients with type 2 diabetes mellitus. Diabetes Metab Syndr Obes. 2014;7:169-183.

7. Lastra G, Syed S, Kurukulasuriya LR, Manrique C, Sowers JR. Type 2 diabetes mellitus and hypertension: an update. Endocrinol Metab Clin North Am. 2014;43(1):103-122.

8. UK Prospective Diabetes Study Group. Tight blood pressure control and risk of macrovascular and microvascular complications in type 2 diabetes: UKPDS 38. BMJ. 1998;317(7160):703-713.

9. Adler AI, Stratton IM, Neil HA, et al. Association of systolic blood pressure with macrovascular and microvascular complications of type 2 diabetes (UKPDS 36): prospective observational study. $B M J$. 2000;321(7258):412-419.

10. Emdin CA, Rahimi K, Neal B, Callender T, Perkovic V, Patel A. Blood pressure lowering in type 2 diabetes: a systematic review and metaanalysis. JAMA. 2015;313(6):603-615. 
11. Rydén L, Grant PJ, Anker SD, et al. ESC guidelines on diabetes, prediabetes, and cardiovascular diseases developed in collaboration with the EASD. Eur Heart J. 2013;34(39):3035-3087.

12. Weber MA, Schiffrin EL, White WB, et al. Clinical practice guidelines for the management of hypertension in the community: a statement by the American Society of Hypertension and the International Society of Hypertension. J Clin Hypertens (Greenwich). 2014;16(1):14-26.

13. Go AS, Bauman MA, King SM, et al. An effective approach to high blood pressure control: a science advisory from the American Heart Association, the American College of Cardiology, and the Centers for Disease Control and Prevention. Hypertension. 2014;63(4):878-885.

14. James PA, Oparil S, Carter BL, et al. 2014 Evidence-based guideline for the management of high blood pressure in adults: report from the panel members appointed to the Eighth Joint National Committee (JNC 8). JAMA. 2014;311(5):507-520.

15. Arguedas JA, Leiva V, Wright JM. Blood pressure targets for hypertension in people with diabetes mellitus. Cochrane Database Syst Rev. 2013;(10):CD008277.

16. Handelsman Y, Bloomgarden ZT, Grunberger G, et al. American Association of Clinical Endocrinologists and American College of Endocrinology: clinical practice guidelines for developing a diabetes mellitus comprehensive care plan -2015. Endocr Pract. 2015;21 Suppl 1:1-87.

17. Daskalopoulou SS, Rabi DM, Zarnke KB, et al. The 2015 Canadian Hypertension Education Program recommendations for blood pressure measurement, diagnosis, assessment of risk, prevention, and treatment of hypertension. Can J Cardiol. 2015;31(5):549-568.

18. Garber AJ, Abrahamson MJ, Barzilay JI, et al. Consensus statement by the American Association of Clinical Endocrinologists and American College of Endocrinology on the comprehensive type 2 diabetes management algorithm: 2016 executive summary. Endocr Pract. 2016;22(1): 84-113.

19. Rosendorff C. Blood pressure targets in patients with diabetes: a new perspective. J Am Soc Hypertens. 2015;9(5):334-336.

20. Xie X, Atkins E, Lv J, et al. Effects of intensive blood pressure lowering on cardiovascular and renal outcomes: updated systematic review and meta-analysis. Lancet. 2016;387(10017):435-443.

21. Casagrande SS, Fradkin JE, Saydah SH, Rust KF, Cowie CC. The prevalence of meeting A1C, blood pressure, and LDL goals among people with diabetes, 1988-2010. Diabetes Care. 2013;36(8):2271-2279.

22. Abdul-Ghani MA, DeFronzo RA. Inhibition of renal glucose reabsorption: a novel strategy for achieving glucose control in type 2 diabetes mellitus. Endocr Pract. 2008;14(6):782-790.

23. DeFronzo RA, Davidson JA, Del Prato S. The role of the kidneys in glucose homeostasis: a new path towards normalizing glycaemia. Diabetes Obes Metab. 2012;14(1):5-14.

24. Vallon V. The mechanisms and therapeutic potential of SGLT2 inhibitors in diabetes mellitus. Annu Rev Med. 2015;66:255-270.

25. Hediger MA, Rhoads DB. Molecular physiology of sodium-glucose cotransporters. Physiol Rev. 1994;74(4):993-1026.

26. Wright EM, Loo DD, Hirayama BA. Biology of human sodium glucose transporters. Physiol Rev. 2011;91(2):733-794.

27. Rahmoune H, Thompson PW, Ward JM, Smith CD, Hong G, Brown J. Glucose transporters in human renal proximal tubular cells isolated from the urine of patients with non-insulin-dependent diabetes. Diabetes. 2005;54(12):3427-3434.

28. Abdul-Ghani MA, Defronzo RA, Norton L. Novel hypothesis to explain why SGLT2 inhibitors inhibit only $30-50 \%$ of filtered glucose load in humans. Diabetes. 2013;62(10):3324-3328.

29. Invokana (canagliflozin) tablets, for oral use [prescribing information]. Titusville, NJ: Janssen Pharmaceuticals, Inc.; 2016.

30. Farxiga (dapagliflozin) tablets, for oral use [prescribing information]. Wilmington, DE: AstraZeneca Pharmaceuticals LP; 2016.

31. Jardiance (empagliflozin) tablets, for oral use [prescribing information] Ridgefield, CT: Boehringer Ingelheim Pharmaceuticals, Inc.; 2016.

32. Yang XP, Lai D, Zhong XY, Shen HP, Huang YL. Efficacy and safety of canagliflozin in subjects with type 2 diabetes: systematic review and meta-analysis. Eur J Clin Pharmacol. 2014;70(10):1149-1158.
33. Zhang M, Zhang L, Wu B, Song H, An Z, Li S. Dapagliflozin treatment for type 2 diabetes: a systematic review and metaanalysis of randomized controlled trials. Diabetes Metab Res Rev. 2014;30(3):204-221.

34. Liakos A, Karagiannis T, Athanasiadou E, et al. Efficacy and safety of empagliflozin for type 2 diabetes: a systematic review and metaanalysis. Diabetes Obes Metab. 2014;16(10):984-993.

35. Whalen K, Miller S, Onge ES. The role of sodium-glucose cotransporter 2 inhibitors in the treatment of type 2 diabetes. Clin Ther. 2015;37(6):1150-1166.

36. Ferrannini E, Muscelli E, Frascerra S, et al. Metabolic response to sodium-glucose cotransporter 2 inhibition in type 2 diabetic patients. $J$ Clin Invest. 2014;124(2):499-508.

37. Merovci A, Solis-Herrera C, Daniele G, et al. Dapagliflozin improves muscle insulin sensitivity but enhances endogenous glucose production. J Clin Invest. 2014;124(2):509-514.

38. Merovci A, Mari A, Solis C, et al. Dapagliflozin lowers plasma glucose concentration and improves $\beta$-cell function. J Clin Endocrinol Metab. 2015;100(5):1927-1932.

39. Cefalu WT, Leiter LA, Yoon KH, et al. Efficacy and safety of canagliflozin versus glimepiride in patients with type 2 diabetes inadequately controlled with metformin (CANTATA-SU): 52 week results from a randomised, double-blind, phase 3 non-inferiority trial. Lancet. 2013;382(9896):941-950.

40. Bolinder J, Ljunggren Ö, Johansson L, et al. Dapagliflozin maintains glycaemic control while reducing weight and body fat mass over 2 years in patients with type 2 diabetes mellitus inadequately controlled on metformin. Diabetes Obes Metab. 2014;16(2):159-169.

41. Ridderstråle M, Andersen KR, Zeller C, Kim G, Woerle HJ, Broedl UC. Comparison of empagliflozin and glimepiride as add-on to metformin in patients with type 2 diabetes: a 104-week randomised, activecontrolled, double-blind, phase 3 trial. Lancet Diabetes Endocrinol. 2014;2(9):691-700.

42. Ferrannini G, Hach T, Crowe S, Sanghvi A, Hall KD, Ferrannini E. Energy balance after sodium-glucose cotransporter 2 inhibition. Diabetes Care. 2015;38(9):1730-1735.

43. Oliva RV, Bakris GL. Blood pressure effects of sodium-glucose co-transport 2 (SGLT2) inhibitors. J Am Soc Hypertens. 2014;8(5):330-339.

44. US Food and Drug Administration. FDA warns that SGLT2 inhibitors for diabetes may result in a serious condition of too much acid in the blood. 2015. Available from: http://www.fda.gov/downloads/Drugs/ DrugSafety/UCM446954.pdf. Accessed January 12, 2016.

45. US Food and Drug Administration. FDA Drug Safety Communication: FDA revises labels of SGLT2 inhibitors for diabetes to include warnings about too much acid in the blood and serious urinary tract infections. 2015. Available from: http://www.fda.gov/Drugs/Drug Safety/ucm475463.htm. Accessed January 12, 2016.

46. Peters AL, Buschur EO, Buse JB, Cohan P, Diner JC, Hirsch IB. Euglycemic diabetic ketoacidosis: a potential complication of treatment with sodium-glucose cotransporter 2 inhibition. Diabetes Care. 2015;38(9):1687-1693.

47. Roach P, Skierczynski P. Euglycemic diabetic ketoacidosis in a patient with type 2 diabetes after treatment with empagliflozin. Diabetes Care. 2016;39(1):e3.

48. Hine J, Paterson H, Abrol E, Russell-Jones D, Herring R. SGLT inhibition and euglycaemic diabetic ketoacidosis. Lancet Diabetes Endocrinol. 2015;3(7):503-504.

49. Erondu N, Desai M, Ways K, Meininger G. Diabetic ketoacidosis and related events in the canagliflozin type 2 diabetes clinical program. Diabetes Care. 2015;38(9):1680-1686.

50. Rosenstock J, Ferrannini E. Euglycemic diabetic ketoacidosis: a predictable, detectable, and preventable safety concern with SGLT2 inhibitors. Diabetes Care. 2015;38(9):1638-1642.

51. Baker WL, Smyth LR, Riche DM, Bourret EM, Chamberlin KW, White WB. Effects of sodium-glucose co-transporter 2 inhibitors on blood pressure: a systematic review and meta-analysis. J Am Soc Hypertens. 2014;8(4):262-275.e9. 
52. Majewski C, Bakris GL. Blood pressure reduction: an added benefit of sodium-glucose cotransporter 2 inhibitors in patients with type 2 diabetes. Diabetes Care. 2015;38(3):429-430.

53. List JF, Woo V, Morales E, Tang W, Fiedorek FT. Sodium-glucose cotransport inhibition with dapagliflozin in type 2 diabetes. Diabetes Care. 2009;32(4):650-657.

54. Lovshin JA, Gilbert RE. Are SGLT2 inhibitors reasonable antihypertensive drugs and renoprotective? Curr Hypertens Rep. 2015;17(6):551.

55. Lambers Heerspink HJ, de Zeeuw D, Wie L, Leslie B, List J. Dapagliflozin a glucose-regulating drug with diuretic properties in subjects with type 2 diabetes. Diabetes Obes Metab. 2013;15(9):853-862.

56. Aucott L, Rothnie H, McIntyre L, Thapa M, Waweru C, Gray D. Longterm weight loss from lifestyle intervention benefits blood pressure? A systematic review. Hypertension. 2009;54(4):756-762.

57. Siebenhofer A, Jeitler K, Berghold A, et al. Long-term effects of weight-reducing diets in hypertensive patients. Cochrane Database Syst Rev. 2011;(9):CD008274.

58. Siebenhofer A, Jeitler K, Horvath K, Berghold A, Siering U, Semlitsch $\mathrm{T}$. Long-term effects of weight-reducing drugs in hypertensive patients. Cochrane Database Syst Rev. 2013;(3):CD007654.

59. Souto-Gallardo ML, Gascón MB, Cruz AJ. Effect of weight loss on metabolic control in people with type 2 diabetes mellitus: systematic review. Nutr Hosp. 2011;26(6):1242-1249.

60. Cefalu WT, Stenlof K, Leiter LA, et al. Effects of canagliflozin on body weight and relationship to HbA1c and blood pressure changes in patients with type 2 diabetes. Diabetologia. 2015;58(6):1183-1187.

61. Vallon V, Richter K, Blantz RC, Thomson S, Osswald H. Glomerular hyperfiltration in experimental diabetes mellitus: potential role of tubular reabsorption. J Am Soc Nephrol. 1999;10(12):2569-2576.

62. Thomson SC, Vallon V, Blantz RC. Kidney function in early diabetes: the tubular hypothesis of glomerular filtration. Am J Physiol Renal Physiol. 2004;286(1):F8-F15.

63. Abdul-Ghani MA, DeFronzo RA. Lowering plasma glucose concentration by inhibiting renal sodium-glucose cotransport. J Intern Med. 2014;276(4):352-363.

64. Škrtić M, Cherney DZ. Sodium-glucose cotransporter-2 inhibition and the potential for renal protection in diabetic nephropathy. Curr Opin Nephrol Hypertens. 2015;24(1):96-103.

65. Chilton R, Tikkanen I, Cannon CP, et al. Effects of empagliflozin on blood pressure and markers of arterial stiffness and vascular resistance in patients with type 2 diabetes. Diabetes Obes Metab. 2015;17(12):1180-1193.

66. Cherney DZ, Perkins BA, Soleymanlou N, et al. The effect of empagliflozin on arterial stiffness and heart rate variability in subjects with uncomplicated type 1 diabetes mellitus. Cardiovasc Diabetol. 2014;13:28.

67. Stenlöf K, Cefalu WT, Kim KA, et al. Efficacy and safety of canagliflozin monotherapy in subjects with type 2 diabetes mellitus inadequately controlled with diet and exercise. Diabetes Obes Metab. 2013;15(4):372-382.

68. Ferrannini E, Ramos SJ, Salsali A, Tang W, List JF. Dapagliflozin monotherapy in type 2 diabetic patients with inadequate glycemic control by diet and exercise: a randomized, double-blind, placebo-controlled, phase 3 trial. Diabetes Care. 2010;33(10):2217-2224.

69. Roden M, Weng J, Eilbracht J, et al. Empagliflozin monotherapy with sitagliptin as an active comparator in patients with type 2 diabetes: a randomised, double-blind, placebo-controlled, phase 3 trial. Lancet Diabetes Endocrinol. 2013;1(3):208-219.

70. Lavalle-González FJ, Januszewicz A, Davidson J, et al. Efficacy and safety of canagliflozin compared with placebo and sitagliptin in patients with type 2 diabetes on background metformin monotherapy: a randomised trial. Diabetologia. 2013;56(12):2582-2592.

71. Bailey CJ, Gross JL, Pieters A, Bastien A, List JF. Effect of dapagliflozin in patients with type 2 diabetes who have inadequate glycaemic control with metformin: a randomised, double-blind, placebo-controlled trial. Lancet. 2010;375(9733):2223-2233.
72. Häring HU, Merker L, Seewaldt-Becker E, et al. Empagliflozin as addon to metformin in patients with type 2 diabetes: a 24-week, randomized, double-blind, placebo-controlled trial. Diabetes Care. 2014;37(6): 1650-1659.

73. Wilding JP, Charpentier G, Hollander P, et al. Efficacy and safety of canagliflozin in patients with type 2 diabetes mellitus inadequately controlled with metformin and sulphonylurea: a randomised trial. Int J Clin Pract. 2013;67(12):1267-1282.

74. Matthaei S, Bowering K, Rohwedder K, Grohl A, Parikh S. Dapagliflozin improves glycemic control and reduces body weight as addon therapy to metformin plus sulfonylurea: a 24-week randomized, double-blind clinical trial. Diabetes Care. 2015;38(3):365-372.

75. Häring HU, Merker L, Seewaldt-Becker E, et al. Empagliflozin as addon to metformin plus sulfonylurea in patients with type 2 diabetes: a 24-week, randomized, double-blind, placebo-controlled trial. Diabetes Care. 2013;36(11):3396-3404.

76. Forst T, Guthrie R, Goldenberg R, et al. Efficacy and safety of canagliflozin over 52 weeks in patients with type 2 diabetes on background metformin and pioglitazone. Diabetes Obes Metab. 2014;16(5):467-477.

77. Rosenstock J, Vico M, Wei L, Salsali A, List JF. Effects of dapagliflozin, an SGLT2 inhibitor, on $\mathrm{HbA}_{1 c}$, body weight, and hypoglycemia risk in patients with type 2 diabetes inadequately controlled on pioglitazone monotherapy. Diabetes Care. 2012;35(7):1473-1478.

78. Kovacs CS, Seshiah V, Swallow R, et al. Empagliflozin improves glycaemic and weight control as add-on therapy to pioglitazone or pioglitazone plus metformin in patients with type 2 diabetes: a 24-week, randomized, placebo-controlled trial. Diabetes Obes Metab. 2014;16(2):147-158.

79. Neal B, Perkovic V, de Zeeuw D, et al. Efficacy and safety of canagliflozin, an inhibitor of sodium-glucose cotransporter 2, when used in conjunction with insulin therapy in patients with type 2 diabetes. Diabetes Care. 2015;38(3):403-411.

80. Wilding JP, Woo V, Soler NG, et al. Long-term efficacy of dapagliflozin in patients with type 2 diabetes mellitus receiving high doses of insulin: a randomized trial. Ann Intern Med. 2012;156(6):405-415.

81. Rosenstock J, Jelaska A, Zeller C, Kim G, Broedl UC, Woerle HJ. Impact of empagliflozin added on to basal insulin in type 2 diabetes inadequately controlled on basal insulin: a 78-week randomized, double-blind, placebo-controlled trial. Diabetes Obes Metab. 2015;17(10):936-948.

82. Weir MR, Januszewicz A, Gilbert RE, et al. Effect of canagliflozin on blood pressure and adverse events related to osmotic diuresis and reduced intravascular volume in patients with type 2 diabetes mellitus. J Clin Hypertens (Greenwich). 2014;16(12):875-882.

83. Sjöström CD, Johansson P, Ptaszynska A, List J, Johnsson E. Dapagliflozin lowers blood pressure in hypertensive and non-hypertensive patients with type 2 diabetes. Diab Vasc Dis Res. 2015;12(5):352-358.

84. Weber MA, Mansfield TA, Cain VA, Iqbal N, Parikh S, Ptaszynska A. Blood pressure and glycaemic effects of dapagliflozin versus placebo in patients with type 2 diabetes on combination antihypertensive therapy: a randomised, double-blind, placebo-controlled, phase 3 study. Lancet Diabetes Endocrinol. 2016;4(3):211-220.

85. Tikkanen I, Narko K, Zeller C, et al. Empagliflozin reduces blood pressure in patients with type 2 diabetes and hypertension. Diabetes Care. 2015;38(3):420-428.

86. Townsend RR, Machin I, Ren J, et al. Reductions in mean 24-hour ambulatory blood pressure after 6-week treatment with canagliflozin in patients with type 2 diabetes mellitus and hypertension. $J$ Clin Hypertens (Greenwich). 2016;18(1):43-52.

87. O’Brien E, Parati G, Stergiou G, et al. European Society of Hypertension position paper on ambulatory blood pressure monitoring. J Hypertens. 2013;31(9):1731-1768.

88. Mancia G, Fagard R, Narkiewicz K, et al. 2013 ESH/ESC guidelines for the management of arterial hypertension: the Task Force for the Management of Arterial Hypertension of the European Society of Hypertension (ESH) and of the European Society of Cardiology (ESC). Eur Heart J. 2013;34(28):2159-2219. 
89. Friedman O, Logan AG. Can nocturnal hypertension predict cardiovascular risk? Integr Blood Press Control. 2009;2:25-37.

90. Lopez JM, Bailey RA, Rupnow MF, Annunziata K. Characterization of type 2 diabetes mellitus burden by age and ethnic groups based on a nationwide survey. Clin Ther. 2014;36(4):494-506.

91. Gavin JR 3rd, Davies MJ, Davies M, Vijapurkar U, Alba M, Meininger G. The efficacy and safety of canagliflozin across racial groups in patients with type 2 diabetes mellitus. Curr Med Res Opin. 2015;31(9):1693-1702.

92. Ferdinand KC, Seman L, Salsali A. Design of a 24-week trial of empagliflozin once daily in hypertensive black/African American patients with type 2 diabetes mellitus. Poster presented at: American Association of Clinical Endocrinologists 25th Annual Meeting; May 25-29, 2016; Orlando, FL.

93. Janssen Research \& Development. Canagliflozin cardiovascular assessment study (CANVAS). Available from: https://www.clinicaltrials.gov/ ct2/show/NCT01032629. NLM identifier: NCT01032629. Accessed January 8, 2016.

94. Neal B, Perkovic V, de Zeeuw D, et al. Rationale, design, and baseline characteristics of the Canagliflozin Cardiovascular Assessment Study (CANVAS): a randomized placebo-controlled trial. Am Heart J. 2013;166(2):217-223.e11.
95. AstraZeneca. Multicenter trial to evaluate the effect of dapagliflozin on the incidence of cardiovascular events (DECLARE-TIMI58). Available from: https://clinicaltrials.gov/ct2/show/NCT01730534. NLM identifier: NCT01730534. Accessed January 8, 2016.

96. TIMI Study Group. DECLARE-TIMI 58. Available from: http:// www.timi.org/index.php?page=declare-timi-58. Accessed April 13, 2016.

97. Merck Sharp \& Dohme. Cardiovascular outcomes following treatment with ertugliflozin in participants with type 2 diabetes mellitus and established vascular disease: the VERTIS CV Study (MK-8835004). Available from: https://www.clinicaltrials.gov/ct2/show/record/ NCT01986881. NLM identifier: NCT01986881. Accessed January 8, 2016.

98. Zinman B, Wanner C, Lachin JM, et al. Empagliflozin, cardiovascular outcomes, and mortality in type 2 diabetes. $N$ Engl J Med. 2015; 373(22):2117-2128.

99. Abdul-Ghani M, Del Prato S, Chilton R, DeFronzo RA. SGLT2 inhibitors and cardiovascular risk: lessons learned from the EMPA-REG OUTCOME study. Diabetes Care. 2016;39(5):717-725.

100. Drazner MH. The progression of hypertensive heart disease. Circulation. 2011;123(3):327-334.
Vascular Health and Risk Management

\section{Publish your work in this journal}

Vascular Health and Risk Management is an international, peerreviewed journal of therapeutics and risk management, focusing on concise rapid reporting of clinical studies on the processes involved in the maintenance of vascular health; the monitoring, prevention and treatment of vascular disease and its sequelae; and the involvement of

\section{Dovepress}

metabolic disorders, particularly diabetes. This journal is indexed on PubMed Central and MedLine. The manuscript management system is completely online and includes a very quick and fair peer-review system, which is all easy to use. Visit http://www.dovepress.com/ testimonials.php to read real quotes from published authors. 